\title{
A Comparison of Châtelperronian and Protoaurignacian Core Technology Using Data Derived from 3D Models
}

\author{
Samantha Thi Porter ${ }^{*}$, Morgan Roussel ${ }^{\dagger}$ and Marie Soressi ${ }^{\dagger}$
}

This study uses data extracted from 3D models to compare blade cores from the Châtelperronian and Protoaurignacian stone tool industries. These technocomplexes are at the center of the debate surrounding the interactions between Neanderthals and anatomically modern humans approximately 45 to 40,000 years ago.

We created 3D models of lithic cores from the sites of Roc de Combe and Les Cottés using a standardized photogrammetry protocol. We then used data derived from these 3D models to make quantitative comparisons of artifact attributes that have previously been argued to distinguish the two stone tool industries in question. These attributes include the angle between the platform and flaking surfaces, the shape of core cross sections, and the angle between core axes. The conception of this study was not to privilege the use of new technological and statistical approaches over more traditional or qualitative forms of lithic analysis. Rather, our aim was to experiment with using digital tool to develop nuanced, reproducible ways to describe variability in lithic artifacts.

Our results support the hypothesis that there is a difference in the angle between core surfaces between these two industries. Our analysis also indicates a difference in the angle between core axes, although we are more cautious in interpreting these results. An elliptical Fourier analysis of core cross section shape was inconclusive. We discuss what archaeological and methodological factors may have contributed to our results, and the roles of both qualitative and quantitative observations in archaeological research. 3D artifact models generated for this study are included as supplemental data and are available for use by other researchers.

Keywords: Neanderthals; lithic technology; elliptical Fourier analysis; 3D scanning; photogrammetry

\section{Introduction}

Over the last decade the field of lithic analysis has seen a surge in the use of digital tools and an increased interest in the application of non-traditional statistical methods. Three-dimensional (3D) scanning has allowed researchers to capture, characterize, and represent artifacts in new ways (e.g. Abel et al. 2011; Buchanan \& Collard 2010; Clarkson \& Hiscock 2011; Lin et al. 2010; Magnani 2014; Morales et al. 2015; Porter et al. 2016; Shott 2014). Researchers have also begun to take advantage of techniques such as geometric morphometrics and landmark analysis (Archer et al. 2018; Davis et al. 2015; Lycett et al. 2006; Lycett \& von Cramon-Taubadel 2013; Shott \& Trail 2010), attribute-based principal components analysis (Scerri 2013), elliptical Fourier analysis (Chacón et al. 2016; Fox 2015; Iovita 2010; Iovita 2011; Iovita \& McPherron 2011; Picin et al. 2014; Putt et al. 2014; Sholts

\footnotetext{
* University of Minnesota, Twin Cities Minneapolis, MN, US

† Leiden University, NL

Corresponding author: Samantha Thi Porter

(stporter@umn.edu)
}

et al. 2012), vector analysis (Bretzke \& Conard 2012; Clarkson et al. 2006), and scar density analysis (Shipton and Clarkson 2015).

One of the largest ongoing discussions in the field of lithic analysis asks how we can move beyond the practice of typing artifacts into discontinuous categories. In Upper Paleolithic contexts, the variability of blades cores is notoriously difficult to describe. Upper Paleolithic cores are often simply typed based on their overall shape as being pyramidal or prismatic (Inizan et al. 1995). Efforts have been made to more finely capture the variability of blade core morphology by describing striking platform angles, the shape of cores in cross section, and the position of the flaking surface relative to the overall volume of the core at discard (e.g. Roussel 2013; Roussel et al. 2016). However, with few exceptions (Bretzke \& Conard 2012) this has almost exclusively been done using qualitative descriptors and manual categorization. Developing sets of continuous variables to capture the diversity in blade core technology would be a significant step forward, and would give researchers an additional tool to better describe and compare artifacts across typologies and technocomplexes in a reproducible manner. 
To this end, in this paper we use data derived from 3D artifact scans to perform quantitative statistical analyses comparing the technologies of two Early Upper Paleolithic industries from France: the Châtelperronian and the Protoaurignacian, which both are dated to approximately 45-40,000 years ago. Châtelperronian lithic technology is acknowledged to be blade based, and thus fully Upper Paleolithic in nature (Roussel et al. 2016). At the same time, there are several observed differences between Châtelperronian technology and the technology of contemporaneous or temporally adjacent industries, namely the Protoaurignacian (Bordes and Teyssandier 2011). It has been suggested that Châtelperronian cores are more prism-like and asymmetrical in section with multiple flaking surfaces, while Protoaurignacian cores tend to be symmetrical, rounded, and have a single continuous flaking surface (Roussel 2013) (Figure 1).

This research focuses on three specific core attributes that have been proposed, primarily via qualitative study, to distinguish Châtelperronian and Protoaurignacian technology. These are the angle between the platform and flaking surfaces, the shape of the core platform in cross section, and the angle between core axes (Figure 2). The definitions of these attributes, their technological context, and the methods we are using are each described in detail in Section 4.

\section{Materials}

\subsection{Collection Context}

The assemblages included in this study originate from two sites central to the debate surrounding the Middle to Upper Paleolithic Transition in Western Europe (Figure 3). The first site, Roc de Combe, is a small cave/rock shelter site located in southwestern France. It was discovered by Labrot in 1950, who began test excavations in 1959. This was followed by a systematic excavation led by F. Bordes and Labrot in 1966 (Bordes \& Labrot 1967).

The material analyzed for this paper derive from the Châtelperronian layer (couche 8) of the final Bordes and Labrot campaign. These materials are currently housed at the Musée National de Préhistoire in Les-Eyzies-de-TayacSireuil, France. This assemblage was also the subject of a seminal analysis of Châtelperronian lithic technology by Pelegrin (1995). A study of the lithic taphonomy of the site by J-G Bordes found evidence of stratigraphic disturbances outside the present dripline of the cave, but concluded sediments closer to the interior cave were largely intact (Bordes 2003). Respective of these results, we only created 3D models of artifacts from this intact zone (rows K-I).

The other two assemblages included in this study come from the site of Les Cottés, which is located in central France. The site is situated around a small cave and has been the subject of archaeological investigations since the 1880s (Lévêque 1997; Pradel 1967). The most recent excavation campaign was begun by Soressi in 2006 and is concentrated around the area just outside of the cave entrance (Soressi et al. 2010).

The sample used for this study includes artifacts from the Châtelperronian (US06) and Protoaurignacian (US 04 inf) layers recovered during the ongoing Soressi excavations (Roussel and Soressi, 2013). There is no evidence of significant stratigraphic mixing between layers. Furthermore, technologically distinct levels are also separated by a series of sterile layers across the site (Soressi et al. 2010; Talamo et al. 2012; Jacobs et al. 2015). As a result, no cores were excluded outright due to their position within the site. Cores were scanned primarily during the 2014 and 2015 field seasons. As many cores as possible were digitized given the time available. Cores that fit pre-determined criteria for inclusion in further analysis (see section 2.2) were given priority.

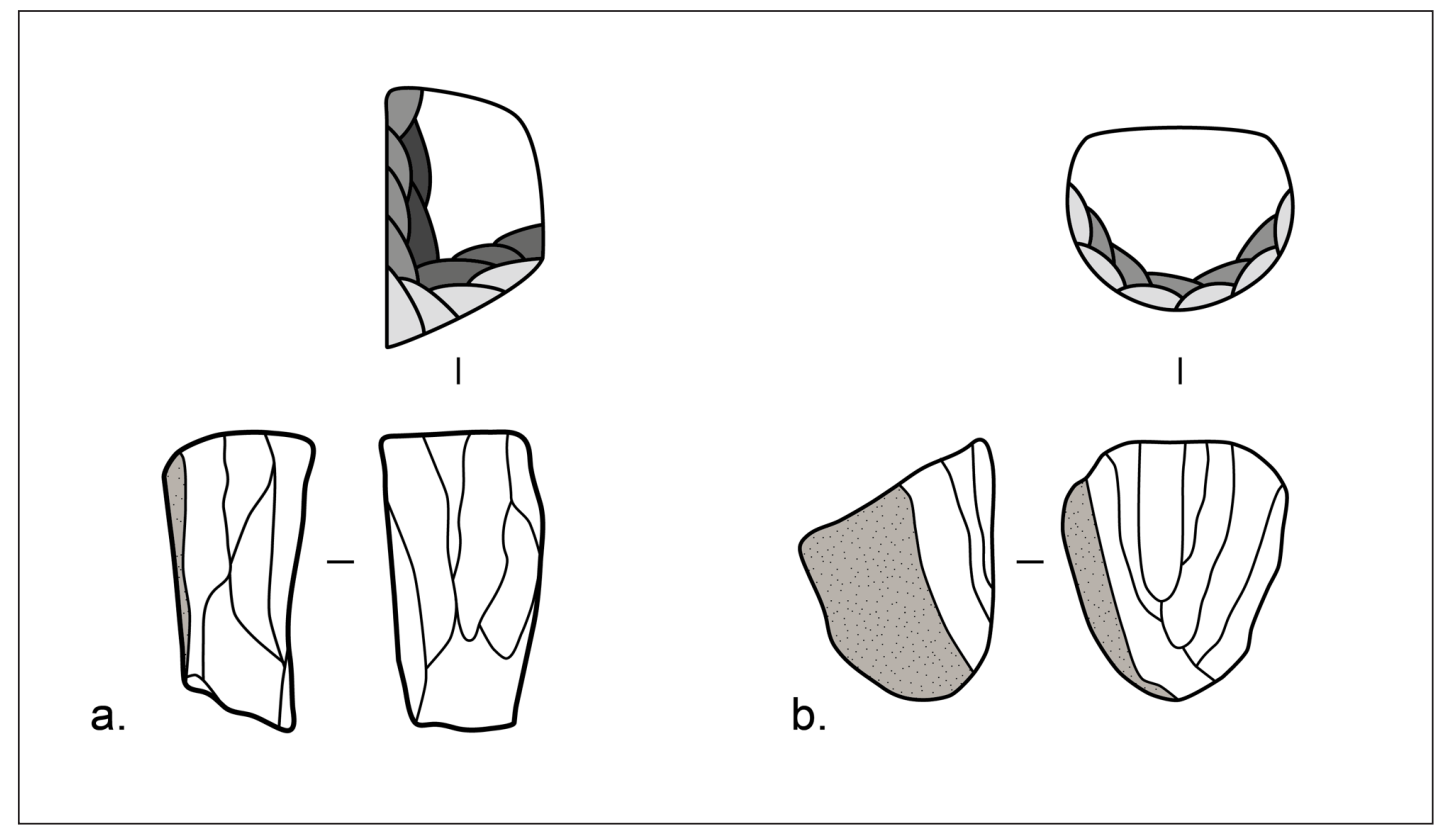

Figure 1: Schematic illustration of idealized Châtelperronian (a) and Protoaurignacian (b) blade cores. Drawn after Bon 2002 (Figure 77, pg. 158); Roussel 2013 (Figure 2, pg. 240); Roussel et al. 2016 (Figure 5b, pg. 21). 


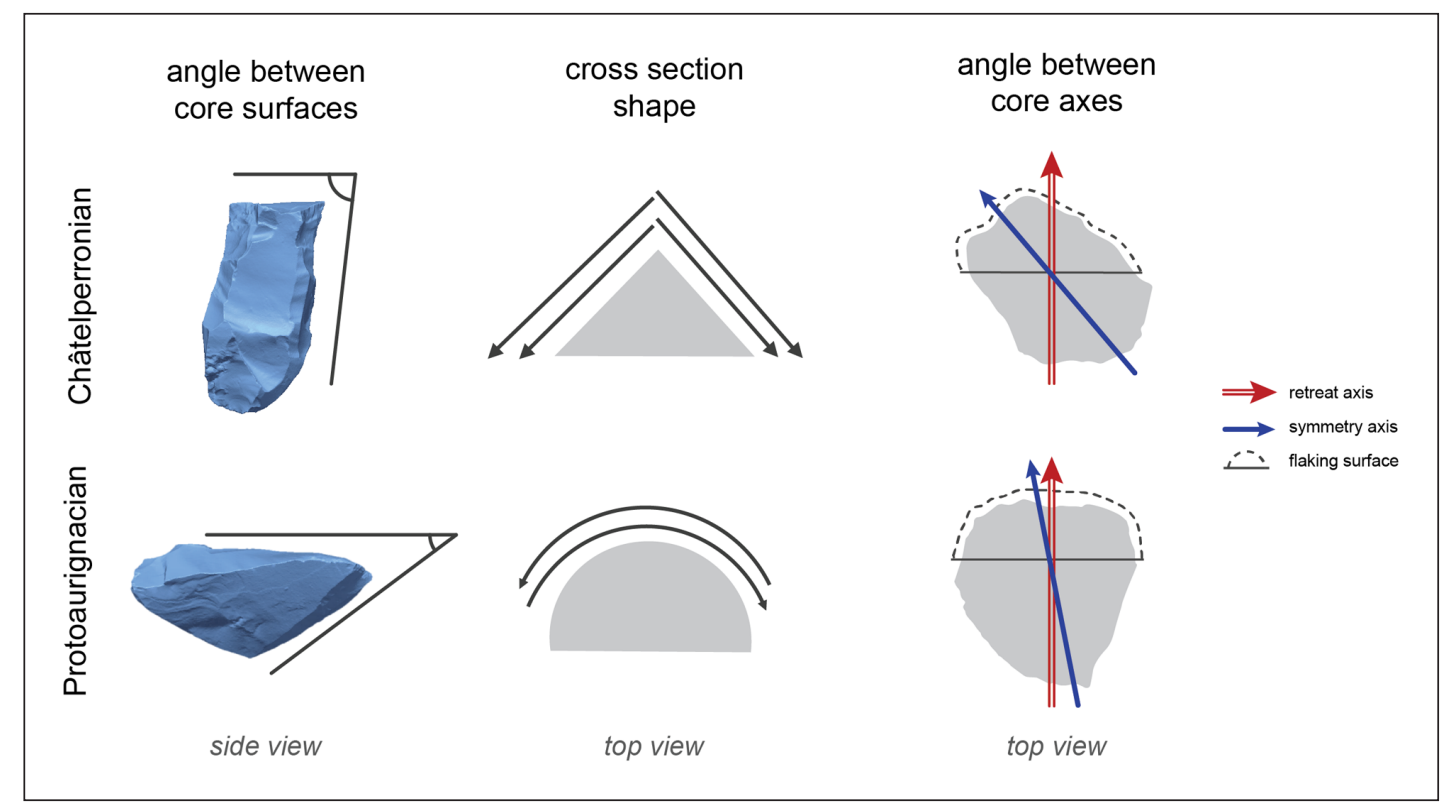

Figure 2: Schematic illustration of the three core attributes being considered in this study. These attributes are described in detail in Section 4.

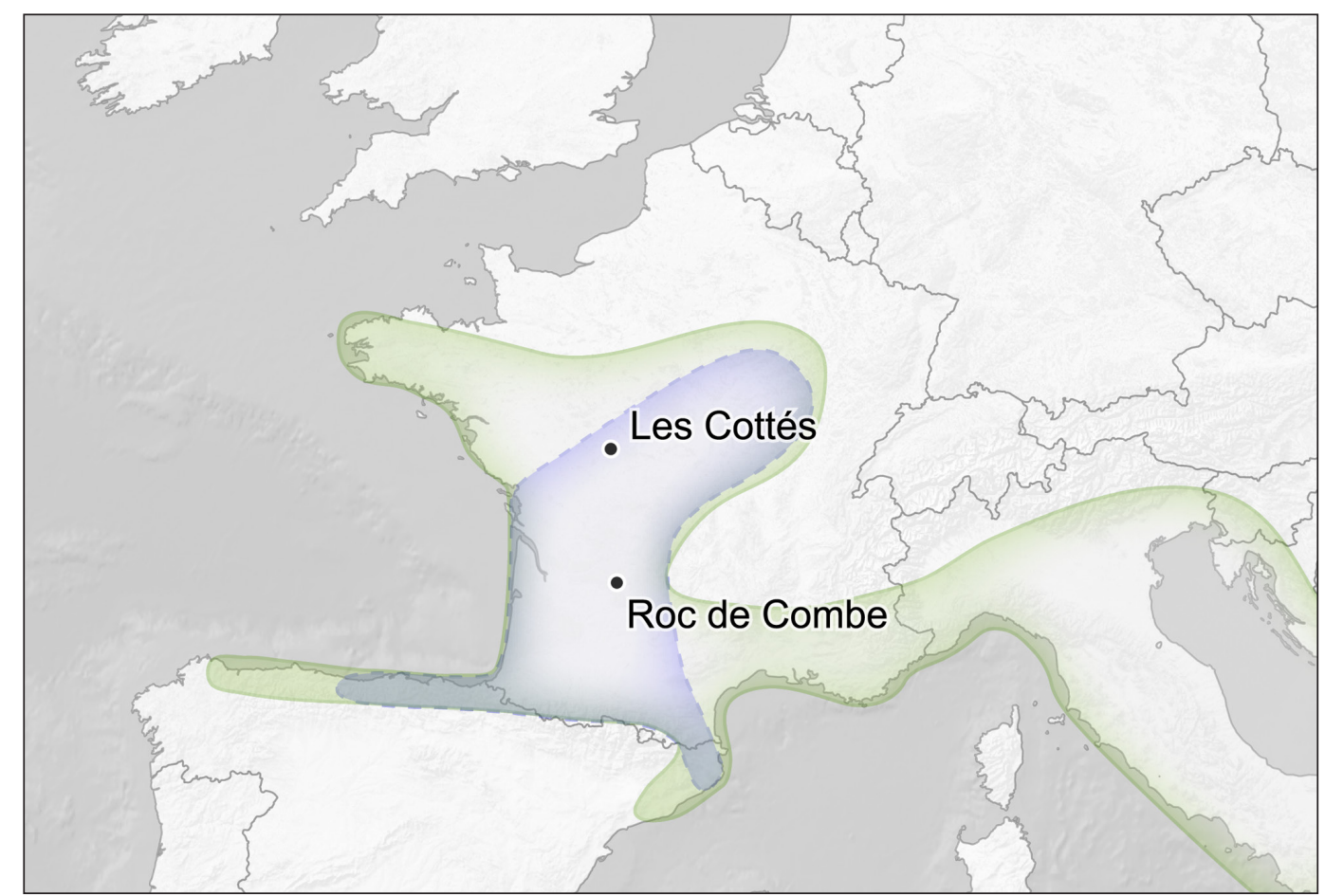

Figure 3: Location of study sites overlaid with the approximate known geographic range of the Châtelperronian (blue with dotted border) and the Protoaurignacian (green with solid border).

\subsection{Artifact Selection Criteria}

In this study, we aimed to maximize the signal of artifact attributes resulting from intentional working by prehistoric knappers. To put it another way, we wanted to limit 'noise' resulting from the natural shape of the material being worked, breaks caused by fissures in the raw material, or knapper error. Thus, we chose to exclude cores that either had little evidence of having anthropogenic modifications, or were broken to the point where blank removals could not be reliably identified. Cores had to have evidence of at least two successful blank (i.e. nonmaintenance) removals not ending in step or hinge fractures.

Based on these criteria, we excluded a large portion of the scanned sample from Roc de Combe. This is largely due to the apparent unrefined nature of the knapping in the core assemblage. In his study of the collection, Pelegrin (1995) suggested this may have been the results of young knappers working the cores after they had been discarded by more experienced group members. Of a total 
of 99 digitized cores, we only included 7 artifacts in our final sample.

Fewer cores were excluded from the Châtelperronian and Protoaurignacian assemblages from Les Cottés. This can be attributed to both the quality of the knapping in the assemblages, and the fact that our selection criteria were decided upon before the majority of the collection had been digitized. We ultimately excluded two cores (X7-408 and Y6-420), which were found in Protoaurignacian layers but appear more characteristically Châtelperronian. Despite the high level of stratigraphic control at Les Cottés, we decided it was safer to exclude these cores to avoid tainting our data. We also cannot rule out the possibility that Protoaurignacian people collected Châtelperronian cores they found lying on the surface of the site. In the end, we included 25 of 41 scanned Châtelperronian cores and 25 of 49 Protoaurignacian cores from Les Cottés in our final sample. All cores included in our study are shown in Figure 4. Contextual information for all digitized artifacts (including those excluded from this study), as well as 3D models of all scanned cores from Les Cottés are freely available for download as part of this article's supplementary information (supplemental files 2-6).

\section{Digitization Methodology}

Models of lithic cores were generated using the technique of close range photogrammetry, also known as structure from motion. Our setup and workflow are described in greater detail in Porter et al. 2016. Initially, photographs were taken with a 12.1 megapixel Canon Powershot sx260 compact digital camera. Roughly midway through data collection, we changed our camera to a 20.2 megapixel Sony RX100i. Since the analyses in this study focus on gross measures of shape as opposed to the quantification of fine morphological details, we think it is unlikely this change in image resolution had an impact on our results. All cores were photographed using manual camera settings. ISO was set as low as possible (100 or 80 ) and the aperture was set to maximize the depth of field of view while minimizing distortion (f.8 or f.11). The camera was placed on a tripod and artifacts were manually rotated on a turntable in front of a black background. LED lights were placed above and to the sides of the artifact in order to minimize shadows.

Lithic artifacts are often made of materials that are shiny, translucent, or very homogenous in nature. These properties can result in lower quality photogrammetric models (Porter et al. 2016). To mitigate these effects, we coated certain cores from the Les Cottés assemblage with a white, water soluble, powder-based spray before photography. Based on availability, we used two different products: Révélateur Skincric R. 764 S1 (a developer spray designed to verify the quality of welds) and Montana Chalk Spray (a spray paint-like product designed to create temporary designs in outdoor environments). Ideally, we would recommend developer spray as chalk spray uses relatively larger particles, which can change the apparent surface texture of resulting 3D models.

Digital photographs were processed into 3D models and scaled using Agisoft PhotoScan, Professional Edition following the procedure described in Porter et al. 2016. A complete list of the artifacts included in this study and metadata for each 3D model is available as supplementary material to this article (supplemental file 2).

\section{Analyses}

\subsection{The Angle between Core Surfaces}

When crafting stone tools, the angle between the core surface being struck (i.e. the platform surface) and the surface from which material is being removed (i.e. the flaking or débitage surface) is one of the most important attributes a knapper must consider, as it is a principal driver of flake morphology (Dibble and Whittaker 1981; Dibble and Rezek 2009; Lin et al. 2013). Based on previous nonmetric observations (Roussel et al. 2016) we hypothesized that the central tendency would be for this angle to be more obtuse (i.e. closer to 90 degrees) in Châtelperronian cores, and more acute in our Protoaurignacian sample.

\subsubsection{Methodology}

Traditionally, angles on lithic artifacts have been measured using a goniometer or have been calculated from caliper measurements. These observations can be difficult to make and can be prone to inter-observer error, particularly when the angle being measured is more acute (Dibble and Bernard 1980). We chose to measure the angle between core surfaces digitally using the software application Geomagic Design X (3D Systems 2015). First, we used the paintbrush selection tool to select polygons corresponding to the area of the platform surface from which there was evidence for blanks having been struck. We used this selection to create a best-fit plane. Next, we looked for the most recent complete flake scar on the face of the core, made a selection of the corresponding polyfaces, and used this selection to create a second best fit plane. Finally, we used Geomagic's measurement tools to calculate the angle between these planes (Figure 5).

\subsubsection{Results}

Our results are shown graphically in Figure 6. As hypothesized, the mean platform angle was higher in the Châtelperronian, although there is a significant overlap in ranges of the raw data. We performed a two-tailed t-test on the combined Châtelperronian sample from Roc de Combe and Les Cottés against the Les Cottés Protoaurignacian. The test resulted in a statistically significant $p$-value $(p=0.0102)$. This supports the hypothesis that there was a difference in the targeted platform angle between Châtelperronian and Protoaurignacian core technology.

\subsubsection{Discussion}

Our hypothesis that Châtelperronian cores have a higher angle between platform and flaking surfaces compared to Protoaurignacian cores was supported. This is to our knowledge the first direct comparison of this metric between these two industries. Although this analysis used a digital measurement method, it focused on an attribute that has traditionally been measured using physical devices (albeit with some difficulty) and has long been recognized as having significance 


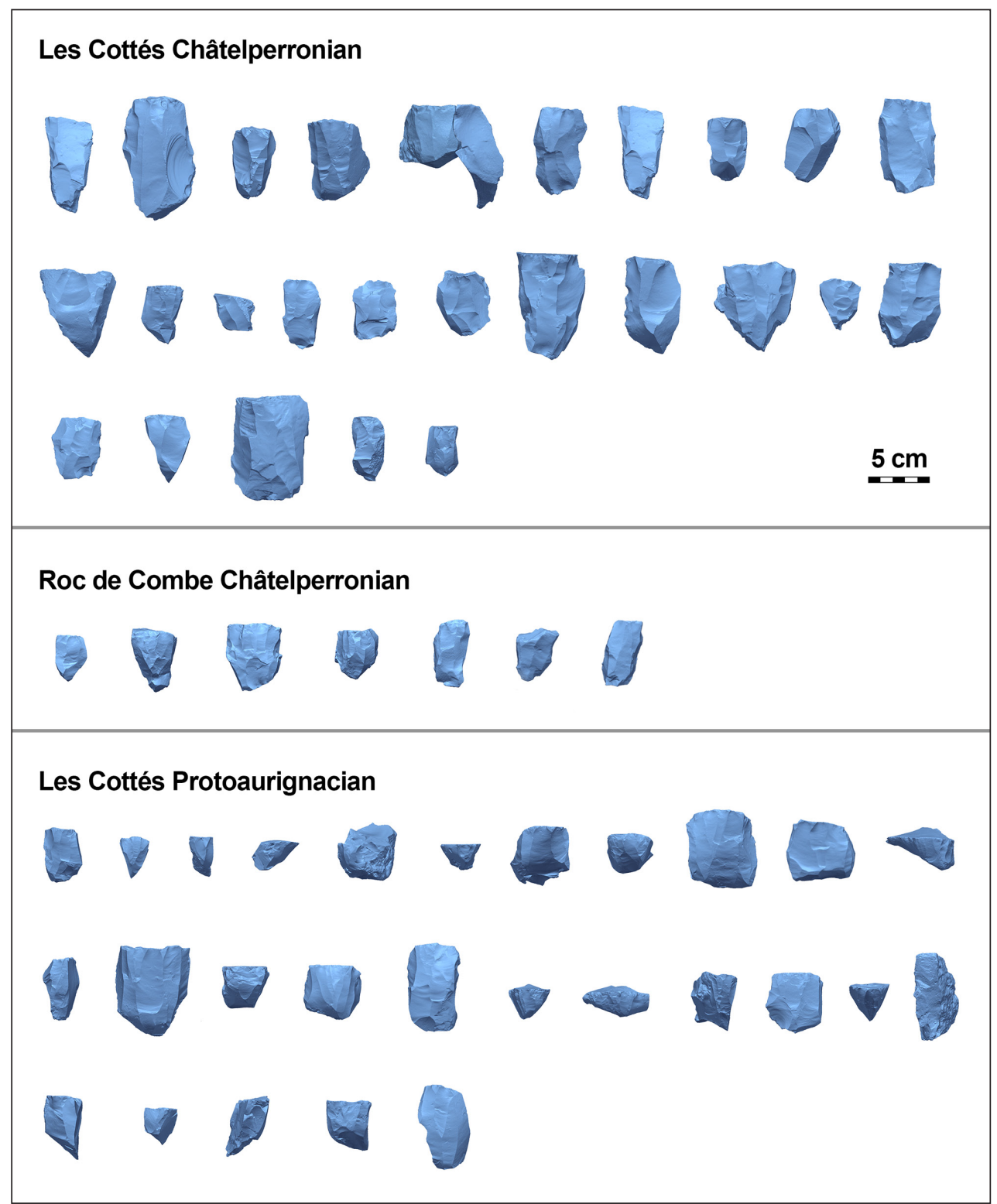

Figure 4: 3D models of the cores included in this study. A list of the artifacts included in this figure can be found in supplemental file 8 .

in the production of lithic artifacts. Going forward, it would be interesting to investigate the relative precision, accuracy, and ease of measurement of digital vs. traditional approaches to angle measurements on three dimensional objects in a similar vein to what has already been done with linear measurements on lithic artifacts (Magnani et al. 2016).

\subsection{Cross section Shape}

Researchers have observed that Châtelperronian and Protoaurignacian blade cores tend to have differently shaped cross sections. It has been proposed that Châtelperronian knappers were specifically seeking asymmetrical blade blanks in order to produce Châtelperronian knives or points (Roussel 2013; Roussel et al. 2016). In order to do this, it is argued that knappers tended to successively work two distinct cores faces. This results in a core with a triangular cross section when viewed from above (Pelegrin 1995; Roussel 2013;
Roussel and Soressi 2010). In contrast, it has been observed that Protoaurignacian knappers tended to work one continuous rounded surface, moving back and forth in what is sometimes called a 'semi-turning' progression (Bon 2002; Roussel 2013; Pigeot 1987). We did not expect to find that knappers followed either of these schemas rigidly. Rather, we were interested in seeing if quantitative shape analysis could pick up any consistent pattern of difference in core shape between the two industries.

\subsubsection{Methodology}

To investigate core cross section shape we used elliptical Fourier analysis, or EFA (Kuhl and Giardina 1982). This method works by fitting an ellipse and series of sine and cosine functions to a closed outline. These functions produce a series of elliptical Fourier descriptors, which can be investigated using several statistical methods. Elliptical Fourier analysis has previously been used in lithic analysis 


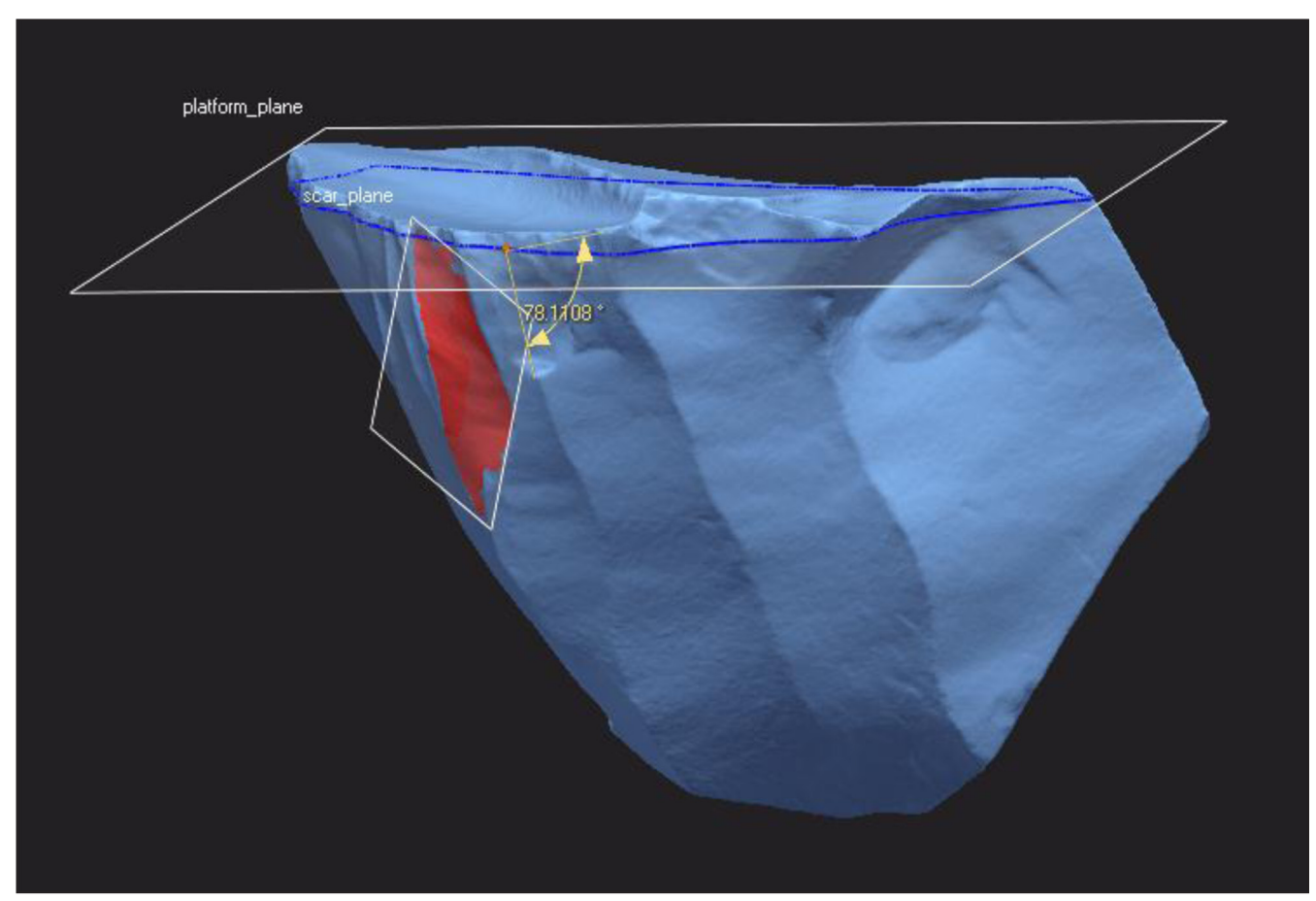

Figure 5: The angle between the platform and flaking surface as measured in Geomagic Design X. The dotted blue line represents the intersection between the platform plane and the core model. The artifact represented is from the Les Cottés Protoaurignacian (CTS_CP_S6-993).

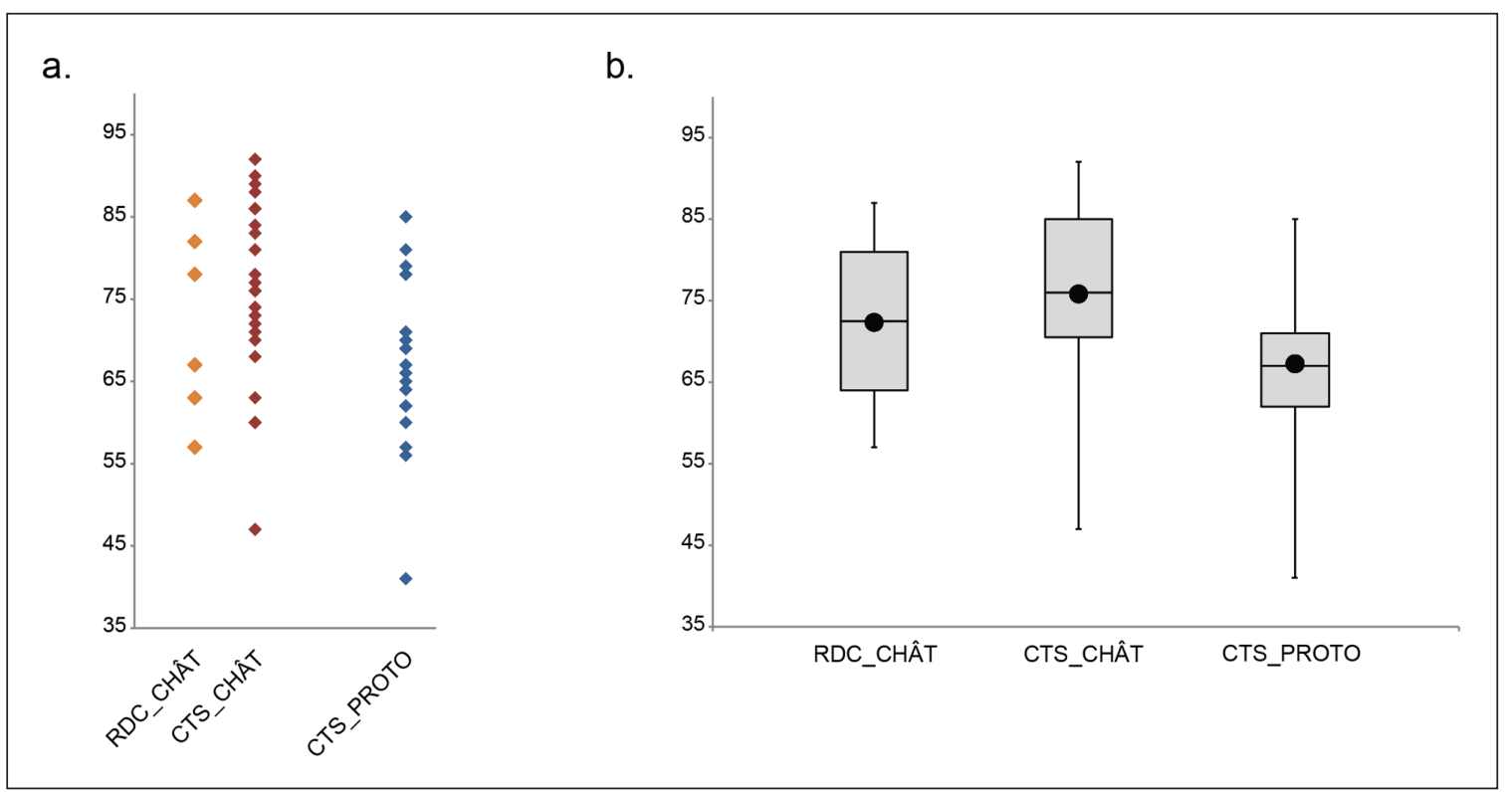

Figure 6: Results of the analysis of the angle between core surfaces: (a) Distribution of raw data; (b) Box plot comparing data from the three different assemblages. The black circle represents the assemblage mean, the box represents the extent of the middle quartiles, and the whiskers represent the minimum and maximum observed values.

to look for patterns in the shape of flakes (Chacón et al. 2016, Picin et al. 2014), unifacial points (Iovita 2011) and bifaces (Fox 2015; Iovita 2010; Iovita and McPherron 2011; Putt et al. 2014; Sholts et al. 2012). To our knowledge, this method has only previously been applied to the shape of lithic artifacts from above in plan view, but not in cross section. We chose to use EFA over landmark-based morphometric techniques since, like most non-biological subjects, core cross sections lack the necessary traits to reliably place landmarks (Bookstein 1991).
We used Geomagic Design X to obtain cross section outlines. We chose to focus on the shape of the platform in cross section (as opposed to the center of the core), since platform shape is more directly controlled by the knapper. We used the same best-fit plane for the platform surface as described in section 4.1. We moved this plane downward along an orthogonal axis to ensure it cut through the entirety of the platform surface. This usually amounted to an offset of around 2-5 mm. We then had Geomagic extract a curve along the intersection of this 
plane and the artifact model. We created reference points marking the furthest extent of the 'worked' area of the platform surface (i.e. the furthest we could find flake scars that resulted from the removal of flake/blade blanks) and drew a vector between these two entities. We chose not to consider the part of the cross section outside of this boundary in our analysis, since the shape of this part of cores is often the result of natural features (e.g. cortical surfaces) as opposed to intentional shaping.

We captured a screenshot of the cross section curve and vector as viewed from above orthogonal to the platform best-fit surface. We also took a screenshot of the entire artifact mesh, which we used in the following analysis (see section 4.3). Next, we imported these screenshots into Adobe Photoshop. We filled in the area bounded by the curve and the vector between the limits of the worked area with black, and added a white background. We then used the layer straightening tool to make the straight portion of each cross section parallel to the bottom of the image. All cross section images used in our study are shown in Figure 7.

These data were analyzed using the software package SHAPE (Iwata and Ukai 2002). First, a chain code was generated using the application ChainCoder. Next, we used the application Chc2Nef to calculate elliptical Fourier descriptors for ten harmonics. We chose this number of harmonics because we wanted to adequately capture the overall shape of our outlines, but did not want small details (e.g. the voids resulting from negative bulbs of percussion) to drive our results.

Chc2Nef provides two options to normalize data (i.e. remove variations in object position, orientation, and size). Outlines can be oriented based on first harmonic or the longest radius. In our case, we wanted orientation to remain as it was in our original black and white images, with the straight edge representing a line drawn between the leftmost and rightmost extents of the worked area facing down and parallel to the bottom of the image. Due to the high amount of variation in our sample, we could not rely on either of the built-in normalization options. To proceed, we normalized our data based on the longest radius, then manually rotated outlines into position (Figure 8). Finally, we conducted a principal components analysis of the resulting elliptical Fourier descriptors using the SHAPE application PrinComp.

\subsubsection{Results}

The results of the PCA for the first three principal components of the analysis are shown in Figure 9. Principal component 1 explains $60.57 \%$ of the variance and appears to be related to whether the platform cross section is more left or right leaning. Principal component 2 explains $31.07 \%$ of the variance and is correlated with the depth of the platform. Principal component 3 does appear to grade between more round and angular cross sections, but explains only $3.54 \%$ of the variance.

A visual inspection of the data shows significant overlap between the Châtelperronian and Protoaurignacian sample across all effective principal component axes. Along PC3 the Châtelperronian sample visually appears to be more angular and the Protoaurignacian sample appears to be rounder, which fits our initial hypothesis. However, this pattern is not statistically significant. A two-tailed Student's t-test assuming equal variance of the principal component values

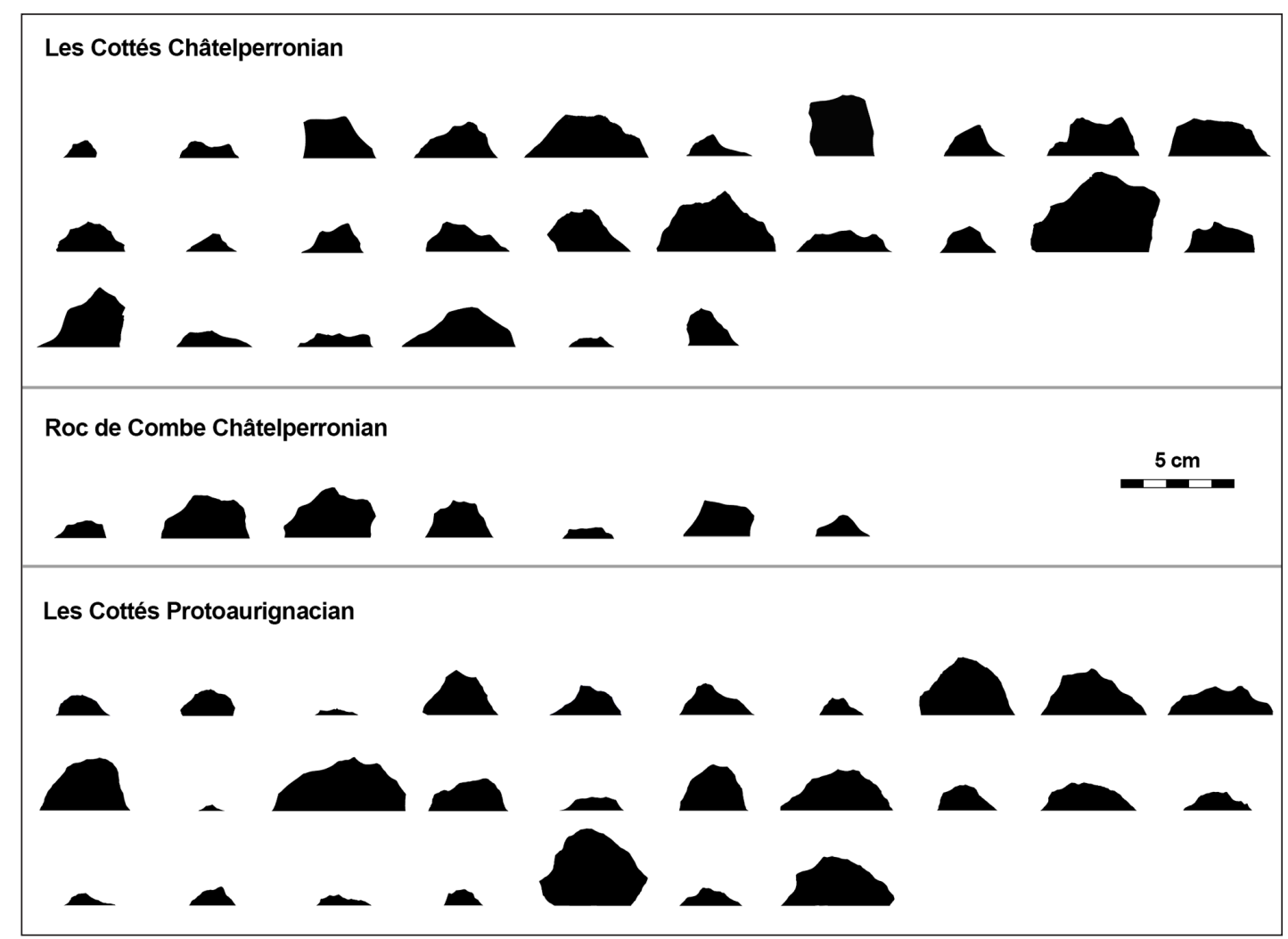

Figure 7: Core cross section images used for elliptical Fourier analysis. 


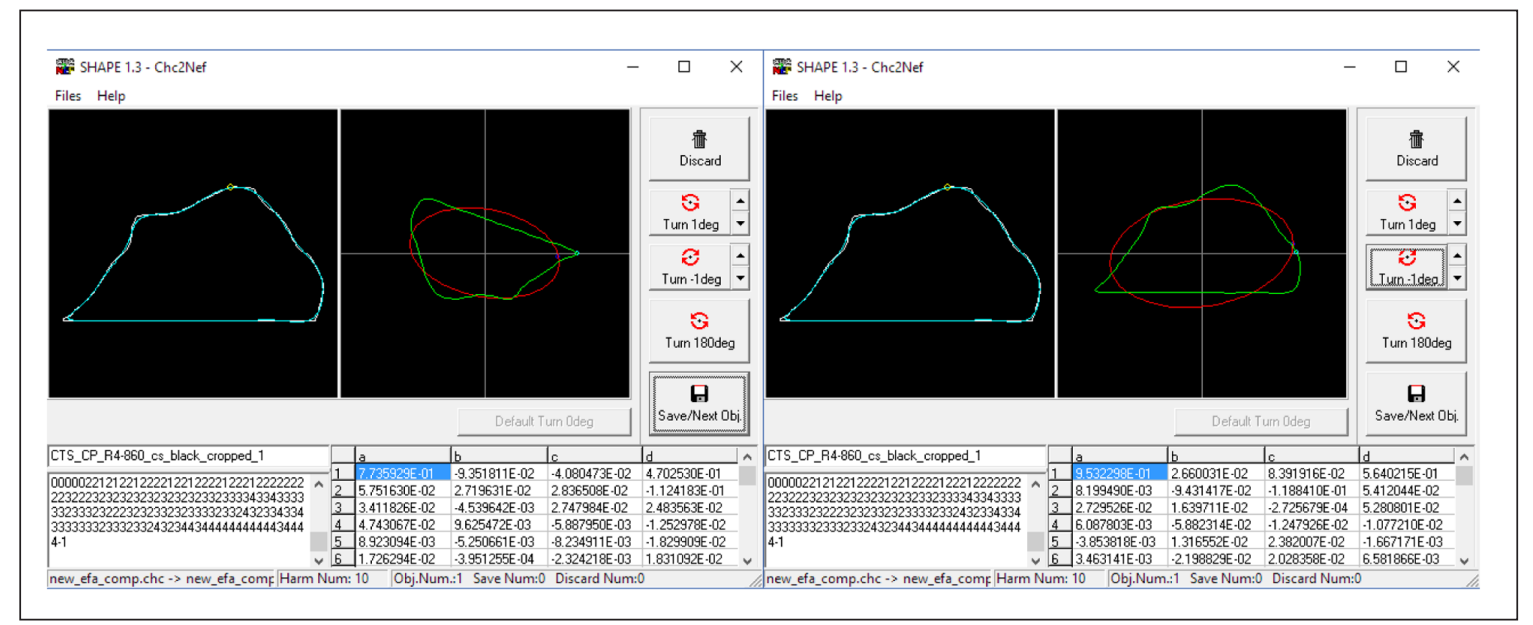

Figure 8: Normalizing core cross section outline data in Chc2Nef: Left) orientation upon import; Right) after manual rotation.

of the combined Châtelperronian and the Protoaurignacian sample on PC3 returned a result of $p=0.804$. This coupled with the low percentage of variation explained by PC3 means this analysis failed to confirm the hypothesized difference in angularity between Châtelperronian and Protoaurignacian cores in cross section.

Because of the diversity of cores in our sample, we wanted to rule out the possibility that artifact size was driving our results. To do this, we used artifact volume as a proxy for size, which we calculated in Geomagic Design $\mathrm{X}$. A plot of our principal component data colored by core volume by quartile once again shows no discernable pattern (Figure 10).

\subsubsection{Discussion}

In this analysis, we used elliptical Fourier analysis to test for differences in the shape of Châtelperronian and Protoaurignacian core cross sections. Based on qualitative observations, it was hypothesized that Châtelperronian core cross sections would be more angular and Protoaurignacian core cross sections would be more rounded. Our analysis revealed no clear patterns. There are many several possible reasons for this.

First, we posit that despite our efforts to refine our sample, core cross sections as defined in this study were heavily influenced by largely non-cultural factors such as raw material quality and availability (Andrefsky 1994; Inizan et al. 1999), and knapper proficiency (Bamforth \& Finlay 2008; Eren et al. 2011; Shelley 1990). Lithic technology is reductive in nature, and mistakes can be difficult to correct. A single errant removal or the location of inclusions or fissures within a nodule can dramatically change core morphology. These factors can force a knapper to abandon a core. It is possible that for our sample, issues arising at the end of the reduction sequence were greater influences on core cross section shape than cultural norms of production.

Although the cross section shape of Paleolithic blade cores is likely the result of culturally and functionally mediated manufacturing traditions, these pressures are arguably much stronger on artifacts such as bifaces and projectile points. There is evidence that these types of objects can serve a culturally communicative purpose
(Wiessner 1983). In many cases, cores are also a byproduct of manufacture, rather than the target of production. The shape of artifacts that are used as tools are more likely to be constrained based on their function. For example, points arguably must be a certain shape and size to effectively serve as projectile tips (Thomas 1978). As a result, it is perhaps then not surprising that most successful applications of EFA in lithic analysis have looked at the shape of these artifact types.

Finally, it is also possible there is simply too much natural variation in core cross section shape to make EFA an effective approach to quantitatively investigating similarities and differences in the volumetric approaches of Paleolithic knappers. Analyses of flake scar orientation (e.g. Bretzke and Conard 2012; Clarkson et al. 2006) could be an alternative avenue to pursue.

\subsection{The Angle between Core Axes}

Our third analysis deals with the relationship between what are known as a core's axis of symmetry and its axis of retreat (Roussel et al. 2016). The axis of symmetry is defined as the axis about which the core is most symmetrical when viewed from above with the platform facing up. The retreat axis is the axis perpendicular to a vector defined by the greatest extents of the flaking surface when the core is viewed from above (Figure 2). Based on qualitative observations, Roussel et al. (2016) posit that because of the reduction strategy used in the Protoaurignacian, the angle between these two axes should be close to zero. In contrast, it is argued that the angle between these axes should be more oblique (i.e. closer to 45 degrees) in the Châtelperronian as a result of a knapping strategy that exploits multiple discreet core surfaces. Once again, our goal with this analysis was to determine if existing qualitative observations could be confirmed quantitatively.

\subsubsection{Methodology}

This analysis utilizes the same black and white platform cross section images obtained for the previous analysis (section 4.2). Additionally, we used a similar Geomagic-toPhotoshop workflow to obtain cross section images of the entire core as viewed from above. We captured these full 


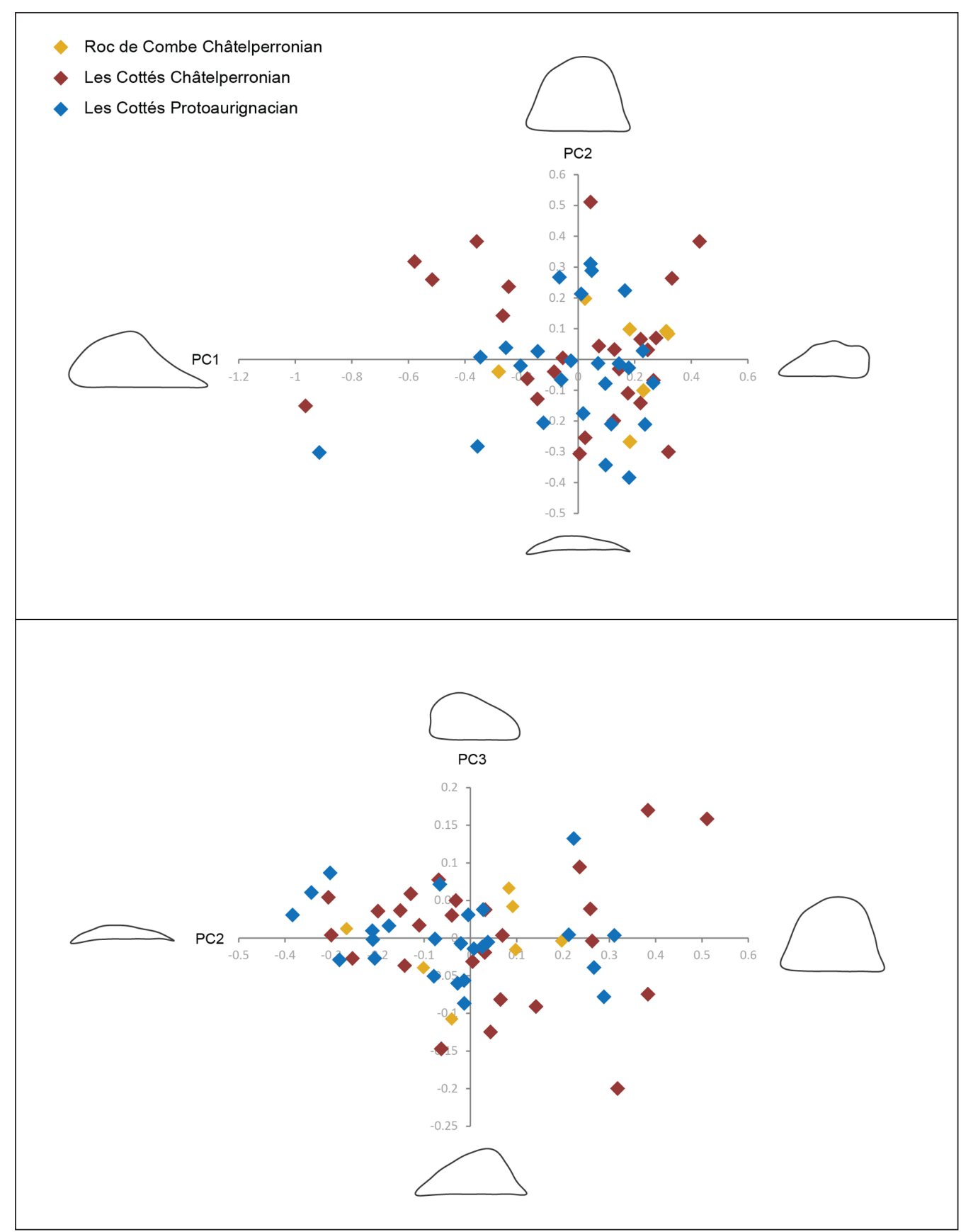

Figure 9: Results of a principal components analysis of the elliptical Fourier core cross section data. Top: comparison of principal components 1 and 2. Bottom: comparison of principal components 2 and 3. The outlines represent extremes 2 standard deviations from the mean contour along each axis.

core screenshots simultaneously with the platform data to ensure both images were taken from the same perspective and at the same scale.

Next, we brought both images into ImageJ (Schneider et al. 2012). We used a macro to draw a vertical line through the center of the platform cross section. This macro works by splitting a selection into equal portions by area (Vischer 2011). We then used the built-in ImageJ macro DrawEllipse to overlay a best-fit ellipse and the major and semi-major axes of this ellipse over the image of the full core. The platform image was then superimposed on the full core image at $50 \%$ opacity. The angle measurement function of ImageJ was then used to measure the angle between the vertical line through the platform cross section and the nearest axis of the best-fit ellipse (Figure 11). All cross section images produced for this analysis are available as part of this article's supplementary materials (supplemental file 7).

\subsubsection{Results}

We performed a two-tailed t-test on the combined Châtelperronian sample from Roc de Combe and Les Cottés, and the Les Cottés Protoaurignacian (Figure 12). This produced a statistically significant $\mathrm{p}$-value $(p=0.0498)$. However, we also performed a two-tailed t-test comparing the Châtelperronian and Protoaurignacian from only Les Cottés. This produced a non-statistically significant result $(p=0.1145)$. If this approach was truly successful in picking up a difference in Châtelperronian and 


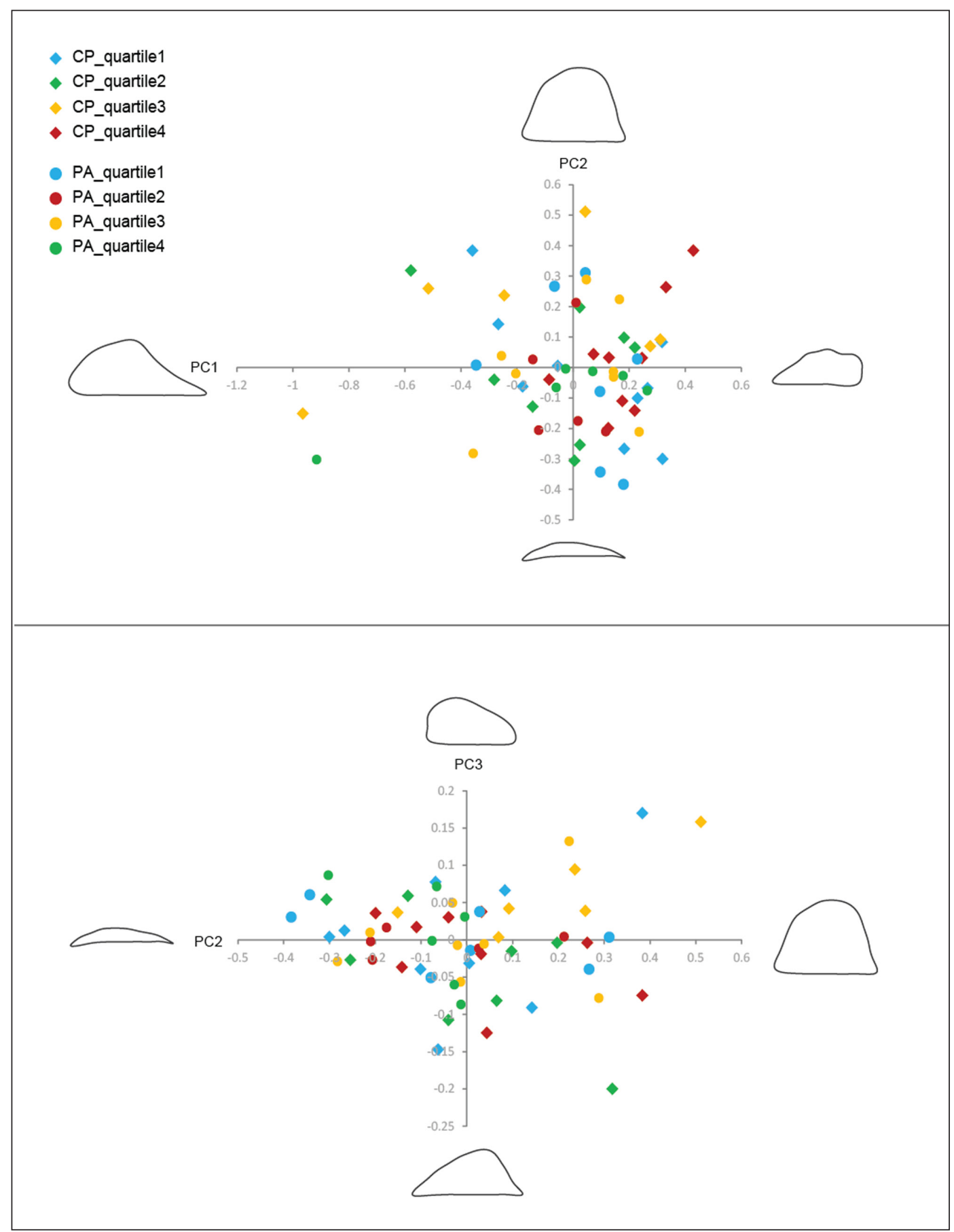

Figure 10: Results of a principal components analysis of the elliptical Fourier data with points colored by core volume by quartile. Quartiles were calculated separately for the combined Châtelperronian (CP) and Protoaurignacian samples (PA). Quartile 1 comprises the smallest $25 \%$ percent of the sample by volume. Quartile 2 comprises the $25^{\text {th }}$ to $50^{\text {th }}$ percentile of the sample by volume. Quartile 3 comprises the $50^{\text {th }}$ to $75^{\text {th }}$ percentile of the sample by volume. Quartile 4 comprises the largest $25 \%$ of the sample by volume.

Protoaurignacian knapping behavior, we would expect this result to be significant, as the analysis removes factors related to site placement that could affect technological choices (e.g. raw material availability and quality). Thus, while we find these results to be promising, we do not believe they are conclusive enough to fully support or refute the hypothesis that there is a difference between Châtelperronian and Protoaurignacian knapping strategies for this attribute.

\subsubsection{Discussion}

Our third analysis tested the hypothesis that the angle between the axis of symmetry and the axis of reduction is higher in Châtelperronian cores than Protoaurignacian cores. While our initial findings support this hypothesis to some extent, for the time being we believe it is safer to view these results with caution. Although a two-tailed t-test of our combined Châtelperronian sample and our Protoaurignacian sample returned a 


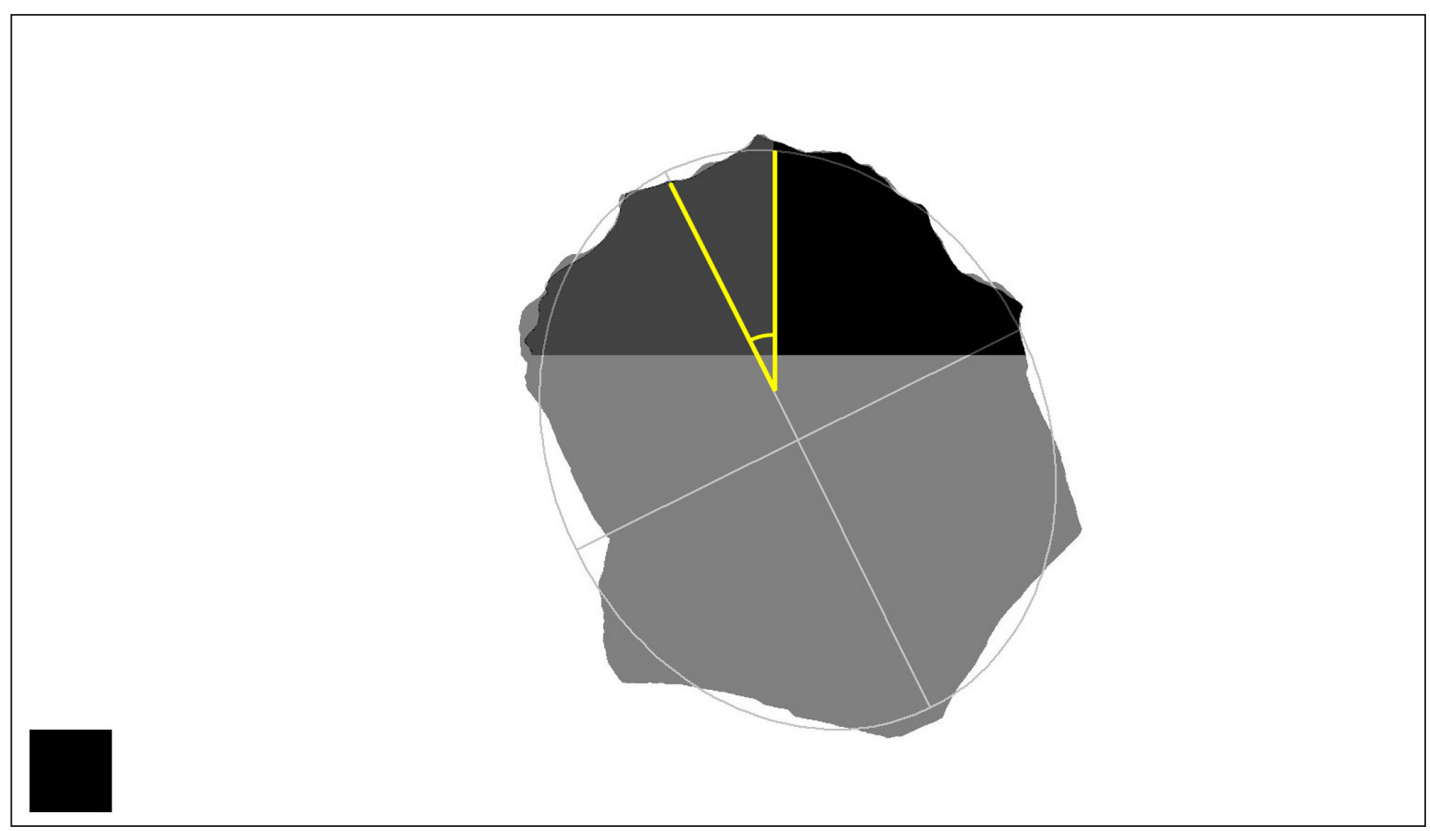

Figure 11: Image exported from ImageJ using the workflow described in section 4.3.1. The measured angle between core axes is marked in yellow. Artifact pictured is CTS_CP_U6-467.

a.

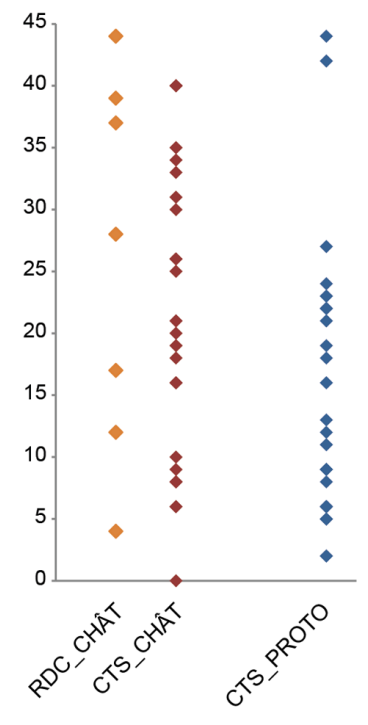

b.

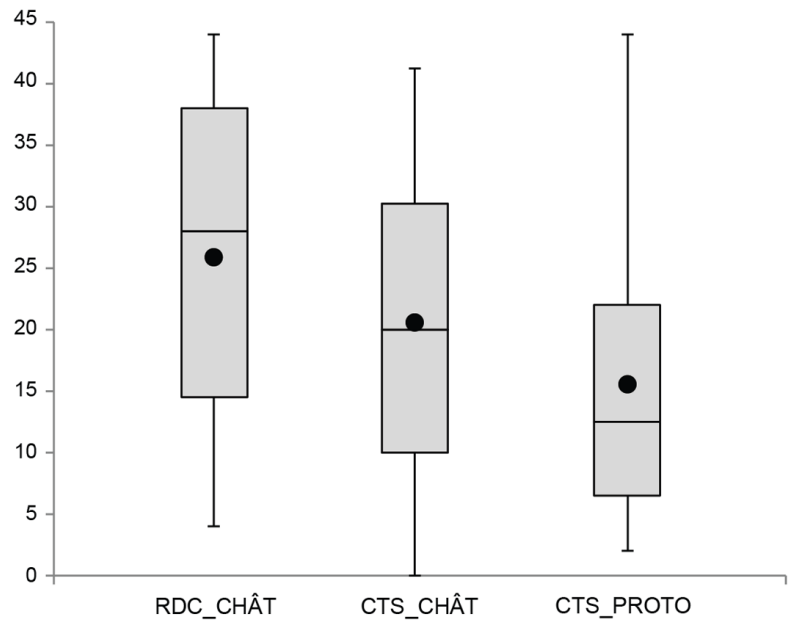

Figure 12: Results of the analysis of the angle between core axes: (a) Distribution of the raw data; (b) Box plot comparing data from the three different assemblages. The black circle represents the assemblage mean.

statistically significant $\mathrm{p}$-value, this was not true of our comparison of the Châtelperronian and Protoaurignacian assemblages from only Les Cottés. A visual inspection of the data shows a high degree of variation within the Châtelperronian samples from both Roc de Combe and Les Cottés (Figure 12). Although the Les Cottés Protoaurignacian sample is concentrated around lower values, there are two potential outliers closer to 45 degrees. We concluded that it was more scientifically conservative not to exclude these artifacts from our statistical analysis. This is because we do not believe our sample size gives us the ability to determine if these specimens are indeed outliers, or if our particular sample did not capture the full range of variation of Protoaurignacian cores. While these results could be used to support our initial hypothesis, we would advocate running this analysis on a larger sample of artifacts from more sites before making any definitive archaeological conclusions.

\section{General Discussion and Conclusion}

This study had multiple goals. First, we aimed to quantitatively test for differences between Châtelperronian and Protoaurignacian cores in three lithic attributes: the angle 
between core surfaces, the shape of core cross sections, and the angle between core axes. While our first analysis did find a statistically significant difference between our Châtelperronian and Protoaurignacian samples, our second and third analyses were somewhat inconclusive.

This leads to our second aim: to explore ways of quantitatively investigating archaeological hypotheses derived from primarily qualitative study. This study demonstrates that while digital quantitative analyses can support qualitative or traditional observations, the application of these techniques is not guaranteed to produce significant results. As both the use of EFA on core cross sections and our method of quantifying the angle between core axes have not previously been attempted, at this time it is difficult to conclusively interpret the meaning of our results, as they could be the consequence of one or more of the following possibilities: a) there is in fact no difference in these aspects of core morphology between the Châtelperronian and Protoaurignacian, b) a difference exists but our sample size was not large or refined enough to statistically demonstrate this difference, c) a difference exists but our method of quantitative analysis was unable to capture it.

To untangle these possibilities, we see several paths forward. A first step would be to increase sample size, ideally incorporating artifact data from additional assemblages and sites. We hope that a trend towards openly publishing 3D artifact models, as we are doing with this paper, will make it easier for researchers in the future to access larger and more diverse datasets. Next, we would advocate more methodological experimentation and the publication of results, especially those that are negative or ambiguous. New ideas only become established methodologies through testing, adaptation, and iteration. These processes are most successful when undertaken as a community.

We emphasize that although this research was quantitative in nature, we are not advocating the point of view that quantitative analyses are inherently superior to qualitative observations, although we do recognize certain quantitative variables are more straightforward to collect in an objective manner. Both types of analysis can inform one another. Quantitative approaches can help researchers make their definitions of qualitative variables more explicit, and thus more reproducible. Above all, results of any type of study should always be interpreted within their greater archaeological context, and these interpretations should remain in conversation with anthropological theory and our understanding of human behavior.

Despite the cautious tone of this paper, we are nothing but optimistic about the future of computers and the application of digital techniques in lithic analysis. We contend that inconclusive results should not be seen as methodological setbacks, but as first steps into a larger world.

\section{Additional File}

The additional file for this article can be found as follows:

- Supplemental data for this paper including 3D models of the Châtelperronian and Protoaurignacian cores from Les Cottés captured for this study are archived on the Data Repository for the University of Minnesota (doi.org/10.13020/D6VD6K). These models are free to be used by others with proper attribution.

\section{Acknowledgements}

We thank Glen Favoretto, Steffen Schatz, Dana Winkler, Kieran McNulty, and Gilbert Tostevin for their contributions to this project. We are grateful to the staff at the Musée National de Préhistoire for access to the Roc de Combe collections and support throughout the data collection process. The Les Cottés excavation project has been funded by the Service Régional de l'Archéologie (France) and by the Department of Human Evolution of the Max Planck Institute for Evolutionary Anthropology. We thank the site owner, J. B., for welcoming our research on his property. This research was made possible by a grant from the Leakey Foundation.

\section{Competing Interests}

The authors have no competing interests to declare.

\section{References}

Abel, RL, Parfitt, S, Ashton, N, Lewis, SG, Scott, B and Stringer, C. 2011. Digital preservation and dissemination of ancient lithic technology with modern micro-CT. Computers and Graphics, 35(4): 878-884. DOI: https://doi.org/10.1016/j. cag.2011.03.001

Andrefsky, W. 1994. Raw-Material Availability and the Organization of Technology. American Antiquity, 59(1): 21-34. DOI: https://doi.org/10.1016/j. cag.2011.03.001

Archer, W, Pop, CM, Rezek, Z, Schlager, S, Lin, SC, Weiss, M, Dogandžić, T, Desta, D and McPherron, SP. 2018. A geometric morphometric relationship predicts stone flake shape and size variability. Archaeological and Anthropological Sciences, 10(8): 1991-2003. DOI: https://doi.org/10.1016/j. cag.2011.03.001

Bamforth, DB and Finlay, N. 2008. Introduction: Archaeological approaches to lithic production skill and craft learning. Journal of Archaeological Method and Theory, 15(1): 1-27. DOI: https://doi. org/10.1007/s 10816-007-9043-3

Bon, F. 2002. L'Aurignacien entre mer et océan: réflexion sur l'unité des phases anciennes de l'Aurignacien dans le sud de la France. Paris: Société Préhistorique Française, Mémoire 29.

Bookstein, F. 1991. Morphometric Tools for Landmark Data: Geometry and Biology. Cambridge: Cambridge University Press.

Bordes, Fand Labrot, J. 1967. La stratigraphie du gisement de Roc de Combe (Lot) et ses implications. Bulletin de La Société Préhistorique Française, 64(1): 15-28. DOI: https://doi.org/10.3406/bspf.1967.4097

Bordes, J. 2003. Lithic taphonomy of the Châtelperronian/Aurignacian interstratifications in 
Roc de Combe and Le Piage. In: Zilhão, J and d'Errico, F (eds.), The Chronology of the Aurignacian and of the Transitional Technocomplexes: Dating, Stratigraphies, Cultural Implications, 33: 223-244. Instituto Português de Arqueologia, Lisboa. Trabalhos de Arqueologia.

Bordes, J-G and Teyssandier, N. 2011. The Upper Paleolithic nature of the Châtelperronian in South-Western France: Archeostratigraphic and lithic evidence. Quaternary International, 246(1-2): 382-388. DOI: https://doi.org/10.1016/j.quaint.2012.03.049

Bretzke, K and Conard, NJ. 2012. Evaluating morphological variability in lithic assemblages using 3D models of stone artifacts. Journal of Archaeological Science, 39(12): 3741-3749. DOI: https://doi. org/10.1016/j.jas.2012.06.039

Buchanan, B and Collard, M. 2010. A geometric morphometrics-based assessment of blade shape differences among Paleoindian projectile point types from western North America. Journal of Archaeological Science, 37(2): 350-359. DOI: https://doi. org/10.1016/j.jas.2009.09.047

Chacón, MG, Détroit, F, Coudenneau, A and Moncel, MH. 2016. Morphometric assessment of convergent tool technology and function during the early middle Palaeolithic: The case of Payre, France. PLOS ONE, 11(5): 1-20. DOI: https://doi.org/10.1371/ journal.pone.0155316

Clarkson, C and Hiscock, P. 2011. Estimating original flake mass from 3D scans of platform area. Journal of Archaeological Science, 38(5): 1062-1068. DOI: https://doi.org/10.1016/j.jas.2010.12.001

Clarkson, C, Vinicius, L and Lahr, MM. 2006. Quantifying flake scar patterning on cores using 3D recording techniques. Journal of Archaeological Science, 33(1): 132-142. DOI: https://doi.org/10.1016/j. jas.2005.07.007

Davis, LG, Bean, DW, Nyers, AJ and Brauner, DR. 2015. GLIMR: A GIS-Based Method for the Geometric Morphometric Analysis of Artifacts. Lithic Technology, 40: 199-217. DOI: https://doi.org/10.1 179/2051618515Y.0000000007

Dibble, $\mathbf{H}$ and Bernard, M. 1980. A comparative study of Basic edge angle measurement techniques. American Antiquity, 45(4): 857-865. DOI: https://doi. org/10.1016/j.jas.2009.05.004

Dibble, H and Rezek, Z. 2009. Introducing a new experimental design for controlled studies of flake formation: results for exterior platform angle, platform depth, angle of blow, velocity, and force. Journal of Archaeological Science, 36: 1945-1954. DOI: https://doi.org/10.1016/j.jas.2009.05.004

Dibble, $\mathbf{H}$ and Whittaker, JC. 1981. New Experimental Evidence on the Relation Between Percussion Flaking and Flake Variation. Journal of Archaeological Science, 8(3): 283-296. DOI: https://doi. org/10.1016/0305-4403(81)90004-2

Eren, MI, Bradley, BA and Sampson, CG. 2011. Middle Paleolithic Skill Level and the Individual
Knapper: An Experiment. American Antiquity, 76(02): 229-251. DOI: https://doi. org/10.1016/0305-4403(81)90004-2

Fox, AN. 2015. A study of Late Woodland projectile point typology in New York using elliptical Fourier outline analysis. Journal of Archaeological Science: Reports, 4: 501-509. DOI: https://doi.org/10.1016/j. jasrep.2015.10.022

Inizan, $\mathbf{L}$, Reduron-Ballingern, $\mathbf{M}$, Roche, $\mathbf{H}$ and Tixier, J. 1999. Technology and Terminology of Knapped Stone. Nanterre: Cercle de Recherches et d'Etudes Préhistorique.

Iovita, R. 2010. Comparing stone tool resharpening trajectories with the aid of elliptical Fourier analysis. In: Lycett, SJ and Chauhan, PR (eds.), New Perspectives on Old Stones, 235-253. New York: Springer. DOI: https://doi. org/10.1007/978-1-4419-6861-6_10

Iovita, R. 2011. Shape variation in Aterian tanged tools and the origins of projectile technology: A morphometric perspective on stone tool function. PloS One, 6(12): e29029. DOI: https://doi. org/10.1371/journal.pone.0029029

Iovita, $\mathbf{R}$ and McPherron, SP. 2011. The handaxe reloaded: A morphometric reassessment of Acheulian and Middle Paleolithic handaxes. Journal of Human Evolution, 61: 61-74. DOI: https://doi. org/10.1016/j.jhevol.2011.02.007

Iwata, H and Ukai, Y. 2002. Shape: A Software Package for Quantitative Evaluation of Biological Shapes Based on elliptic Fourier descriptors. Journal of Heredity, 93(5): 384-385. DOI: https://doi.org/10.1093/ jhered/93.5.384

Jacobs, Z, Li, B, Jankowski, N and Soressi, M. 2015. Testing of a single grain OSL chronology across the Middle to Upper Palaeolithic transition at Les Cottés (France). Journal of Archaeological Science, 54: 110-122. DOI: https://doi.org/10.1016/j.jas.2014.11.020

Kuhl, FP and Giardina, CR. 1982. Elliptic Fourier Features of a Closed Contour. Computer Graphics and Image Processing, 18: 236-258. DOI: https:// doi.org/10.1016/0146-664X(82)90034-X

Levêque, F. 1997. Le Passage du Paléolithique moyen au Paléolithique supérieur: Données stratigraphiques de quelques gisements sous-grotte du sud-ouest. Quaternaire, 8: 279-287. DOI: https://doi. org/10.3406/quate.1997.1580

Lin, SC, Rezek, Z, Braun, D and Dibble, H. 2013. On the utility and economization of unretouched flakes: The effects of exterior platform angle and platform depth. American Antiquity, 78(4): 724-745.

Lin, SCH, Douglass, MJ, Holdaway, SJ and Floyd, B. 2010. The application of 3D laser scanning technology to the assessment of ordinal and mechanical cortex quantification in lithic analysis. Journal of Archaeological Science, 37(4): 694-702. DOI: https://doi.org/10.1016/j.jas.2009.10.030

Lycett, SJ and von Cramon-Taubadel, N. 2013. A 3D morphometric analysis of surface geometry in 
Levallois cores: Patterns of stability and variability across regions and their implications. Journal of Archaeological Science, 40(3): 1508-1517. DOI: https://doi.org/10.1016/j.jas.2012.11.005

Lycett, SJ, von Cramon-Taubadel, N and Foley, RA. 2006. A crossbeam co-ordinate caliper for the morphometric analysis of lithic nuclei: A description, test and empirical examples of application. Journal of Archaeological Science, 33(6): 847-861. DOI: https://doi.org/10.1016/j.jas.2005.10.014

Magnani, M. 2014. Three-Dimensional Alternatives to Lithic Illustration. Advances in Archaeological Practice, 2(4): 285-297. DOI: https://doi. org/10.7183/2326-3768.2.4.285

Magnani, M, Douglass, M and Porter, ST. 2016. Closing the seams: resolving frequently encountered issues in photogrammetric modelling. Antiquity, 90(354): 1654-1669. DOI: https://doi.org/10.15184/ aqy.2016.211

Morales, JI, Lorenzo, C and Vergès, JM. 2015. Measuring Retouch Intensity in Lithic Tools: A New Proposal Using 3D Scan Data. Journal of Archaeological Method and Theory, 22(2): 543-558. DOI: https:// doi.org/10.1007/s 10816-013-9189-0

Pelegrin, J. 1995. Technologie lithique: le Châtelperronien de Roc-de-Combe (Lot) et de la Côte (Dordogne). Paris: CNRS.

Picin, A, Vaquero, M, Weniger, GC and Carbonell, E. 2014. Flake morphologies and patterns of core configuration at the Abric Romaní rock-shelter: A geometric morphometric approach. Quaternary International, 350: 84-93. DOI: https://doi. org/10.1016/j.quaint.2014.05.004

Pigeot, N. 1987. Magdaléniens d'Étiolles. Économie de débitage et organisation sociale. Paris: CNRS.

Porter, ST, Roussel, M and Soressi, M. 2016. A Simple Photogrammetry Rig for the Reliable Creation of 3D Artifact Models in the Field. Advances in Archaeological Practice, 4(1): 71-86. DOI: https:// doi.org/10.7183/2326-3768.4.1.71

Pradel, L. 1967. La grotte des Cottés, commune de Saint-Pierre-de-Maillé (Vienne), Moustérien, Périgordien, Aurignacien, dations par le radiocarbone. L'Anthropologie, 71: 271-277.

Putt, SS, Woods, AD and Franciscus, RG. 2014. The role of verbal interaction during experimental bifacial stone tool manufacture. Lithic Technology, 39(2): 96-112. DOI: https://doi.org/10.1179/01977261 14Z.00000000036

Roussel, M. 2013. Méthodes et rythmes du débitage laminaire au Châtelperronien: Comparaison avec le Protoaurignacien. Comptes Rendus Palevol, 12: 233-241. DOI: https://doi.org/10.1016/j. crpv.2013.02.004

Roussel, M and Soressi, M. 2010. La Grande Roche de la Plématrie à Quinçay (Vienne). L'évolution du Châtelperronien revisitée. In: Buisson-Catil, J and Primault, J (eds.), Préhistoire Entre Vienne et Charente. Hommes et Sociétés Du Paléolithique, 38:
203-219. Chauvigny: Association des Publications Chauvinoises, Mémoire.

Roussel, M and Soressi, M. 2013. Une nouvelle séquence du Paléolithique supérieur ancien aux marges sudouest du Bassin parisien: Les Cottés dans la Vienne. In: Le Paléolithique supérieur ancien de l'Europe du Nord-ouest, Bodu, P, Chehmana, L, Klaric, L, Mevel, L, Soriano, $\mathrm{S}$ and Teyssandier, N (eds.), Société Préhistorique Française, Paris, Mémoirem, 56: 283-298.

Roussel, M, Soressi, M and Hublin, JJ. 2016. The Châtelperronian conundrum: Blade and bladelet lithic technologies from Quinçay, France. Journal of Human Evolution, 95: 13-32. DOI: https://doi. org/10.1016/j.jhevol.2016.02.003

Scerri, EML. 2013. The Aterian and its place in the North African Middle Stone Age. Quaternary International, 300: 111-130. DOI: https://doi.org/10.1016/j. quaint.2012.09.008

Schneider, CA, Rasband, WS and Eliceiri, KW. 2012. $\mathrm{NIH}$ Image to ImageJ: 25 years of image analysis. Nature Methods, 9(7): 671-675. DOI: https://doi. org/10.1038/nmeth.2089

Shelley, PH. 1990. Variation in Lithic Assemblages: An Experiment. Journal of Field Archaeology, 17(2): 187-193. DOI: https://doi. org/10.1179/009346990791548349

Shipton, C and Clarkson, C. 2015. Flake scar density and handaxe reduction intensity. Journal of Archaeological Science: Reports, 2: 169-175. DOI: https://doi.org/10.1016/j.jasrep.2015.01.013

Sholts, SB, Stanford, DJ, Flores, LM and Wärmländer, SKTS. 2012. Flake scar patterns of Clovis points analyzed with a new digital morphometrics approach: Evidence for direct transmission of technological knowledge across early North America. Journal of Archaeological Science, 39(9): 3018-3026. DOI: https://doi.org/10.1016/j.jas.2012.04.049

Shott, M. 2014. Digitizing archaeology: A subtle revolution in analysis. World Archaeology, 46(1): 1-9. DOI: https://doi.org/10.1080/00438243.201 3.879046

Shott, MJ and Trail, BW. 2010. Exploring New Approaches to Lithic Analysis: Laser Scanning and Geometric Morphometrics. Lithic Technology, 35(2): 195-220. DOI: https://doi.org/10.1080/01977261.2010.1172 1090

Soressi, M, Roussel, M, Rendu, W, Primault, J, Rigaud, S, Texier, J-P, Richter, D, Talamo, S, Ploquin, F, Larmignat, B, Tavormina, C and Hublin, JJ. 2010. Les Cottés (Vienne). Nouveaux travaux sur l'un des gisements de référence pour la transition Paléolithique moyen/supérieur. In: Buisson-Catil, $\mathrm{J}$ and Primault, J (eds.), Préhistoire Entre Vienne et Charente. Hommes et Sociétés Du Paléolithique, 38: 221-234. Chauvigny: Association des Publications Chauvinoises, Mémoire.

Talamo, S, Soressi, M, Roussel, M, Richards, $\mathbf{M}$ and Hublin, JJ. 2012. A radiocarbon chronology for the complete Middle to Upper Palaeolithic 
transitional sequence of Les Cottés (France). Journal of Archaeological Science, 39(1): 175-183. DOI: https://doi.org/10.1016/j.jas.2011.09.019

Thomas, DH. 1978. Arrowheads and Atlatl Darts: How the Stones Got the Shaft. American Antiquity, 43(3): 461-472. DOI: https://doi. org $/ 10.2307 / 279405$
Vischer, N. 2011. Re: ROI post processing help: Split in two equal surfaces. Code retrieved January 23, 2018. from: http://imagej.1557.x6.nabble.com/ROI-post-processing-help-split-in-two-equal-surfaces-td3685206.html.

Wiessner, P. 1983. Style and Social Information in Kalahari San Projectile Points. American Antiquity, 48(2): 253-276. DOI: https://doi.org/10.2307/280450

How to cite this article: Porter, ST, Roussel, M and Soressi, M. 2019. A Comparison of Châtelperronian and Protoaurignacian Core Technology Using Data Derived from 3D Models. Journal of Computer Applications in Archaeology, 2(1), pp. 41-55. DOI: https://doi. org/10.5334/jcaa.17

Submitted: 13 July 2018 Accepted: 29 January 2019 Published: 20 March 2019

Copyright: ( 2019 The Author(s). This is an open-access article distributed under the terms of the Creative Commons Attribution 4.0 International License (CC-BY 4.0), which permits unrestricted use, distribution, and reproduction in any medium, provided the original author and source are credited. See http://creativecommons.org/licenses/by/4.0/. 